\title{
Percutaneous Nephrolithotomy in the Superobese: A Comparison of Outcomes Based on Body Mass Index
}

\author{
Casey A. Dauw, MD, Michael S. Borofsky, MD, Nadya York, MD, and James E. Lingeman, MD, FACS
}

\begin{abstract}
Introduction: Percutaneous nephrolithotomy (PCNL) is considered the gold standard for treatment of large renal calculi. Although several investigators have examined the feasibility and outcomes associated with PCNL in obese patients, these studies have been limited by small sample size, lack of a comparator group, or few patients at body mass index (BMI) extremes. We thus compared outcomes of superobese (BMI >50) patients undergoing PCNL vs both an "overweight" and "ideal" cohort.

Methods: We used a prospectively maintained database to identify ideal (BMI 18.5-25), overweight (BMI 25.1-49.9), and superobese (BMI $\geq 50$ ) patients who underwent PCNL. Our primary objective was to compare surgical outcomes between groups measured by the percent of patients who required secondary PCNL. We then compared complication rates, need for transfusion, and length of stay (LOS) using chi-square testing and ANOVA where appropriate.

Results: A total of 1152 patients were identified of which 254 were classified as ideal, 840 as overweight, and 58 as superobese. The overweight cohort had a higher mean age and greater proportion of males, whereas staghorn stones were more common in the superobese group. Comorbid conditions were more commonly observed in the superobese cohort. Otherwise, the groups were similar. Surgical outcomes were comparable with $47.2 \%, 42.0 \%$, and $38.0 \%$ of ideal, overweight, and superobese patients requiring secondary PCNL $(p=0.25)$ with no difference in complication rates, need for transfusion, or LOS.

Conclusion: PCNL can be effectively and safely performed in superobese patients with no difference in surgical outcomes or complications when compared to ideal or overweight patient cohorts.
\end{abstract}

\section{Introduction}

A LTHOUGH THERE ARE several surgical modalities available for the treatment of renal calculi, percutaneous nephrolithotomy (PCNL) remains the reference standard for treatment of large stones, particularly those greater than $2 \mathrm{~cm}$ in size. ${ }^{1,2}$ Indeed, a multitude of studies have been conducted, which clearly indicate the effectiveness of PCNL, while maintaining an acceptable safety profile. ${ }^{3-5}$ Importantly, these outcomes remain favorable despite stone configuration, size, location, or composition, which stands in stark contrast to other surgical modalities, namely shock wave lithotripsy. ${ }^{6,7}$

Over the past few decades, obesity, defined as a body mass index (BMI, $\mathrm{kg} / \mathrm{m}^{2}$ ) greater than 30 , has become increasingly prevalent, reaching epidemic proportions. ${ }^{8}$ Given the association between obesity, metabolic syndrome, and kidney stones, ${ }^{9,10}$ these patients commonly present with large renal stones for which PCNL is the optimal surgical treatment. ${ }^{11}$ Several studies have documented the feasibility, safety, and efficacy of PCNL in obese patients. ${ }^{12-14}$ However, limitations such as small sample size, ${ }^{15}$ lack of comparator groups, ${ }^{16,17}$ or few patients at BMI extremes ${ }^{18}$ have led some experts to assert that alternative treatment modalities, namely flexible ureteroscopy, be considered first-line therapy. ${ }^{19}$

Herein, we present our experience and outcomes following PCNL in patients across a wide range of BMI from a large, single-institutional contemporary dataset. Particular attention is focused on superobese patients - those with a BMI greater than or equal to 50-in whom PCNL can be exceptionally challenging. Findings from this study are intended to bolster the existing evidence that PCNL is an acceptable and efficacious treatment for large renal stones irrespective of BMI and should be considered the standard treatment approach for these patients.

\section{Materials and Methods}

\section{Data source and study population}

Using a prospectively maintained, institutional review boardapproved database (Methodist Hospital IRB\#1010002243), we identified all adult patients who had undergone unilateral or

Department of Urology, Indiana University School of Medicine, Indianapolis, Indiana. 
bilateral PCNL at a single tertiary referral center. This dataset includes over 1250 consecutive patients enrolled from the year 2003 to 2015 and treated by 13 surgeons.

Since our primary focus was to determine how BMI might impact surgical outcomes, we further stratified patients into three groups. Patients were categorized as ideal if their BMI was 18.5 to 24.9, overweight if BMI was 25 to 49.9, or superobese if BMI was greater than or equal to 50. Patients with a BMI less than 18.5 were excluded. A wide range of BMI was intentionally included in the overweight cohort since prior studies have not documented any difference in outcomes for PCNL in patients with BMI ranging from 25 to, in excess of, 40 and this allowed for a larger sample size for comparison to the ideal and superobese cohorts. ${ }^{13}$

\section{Surgical considerations and hospital course}

Our surgical technique has been described in detail in other reports. ${ }^{20,21}$ In brief, following induction of general anesthesia, patients are positioned in the lithotomy position such that a $5 \mathrm{~F}$ ureteral catheter can be advanced in a retrograde manner into the renal unit of interest to facilitate delineation of caliceal anatomy. The patient is then positioned prone and secured to the operating room table. A retrograde study is performed and the calix of puncture, typically posteriorly oriented and lower pole, is selected. Access is obtained using an 18-gauge diamond tip needle, biplanar fluoroscopy, and triangulation technique, while respiration is suspended.

After confirmation of entry into the collecting system by aspiration of urine, a hydrophilic wire is negotiated down the ureter with the aid of an angiographic catheter, if necessary. The wire is exchanged for an Amplatz Super Stiff wire (Boston Scientific Corp, Natick, MA) and an 8-10F coaxial dilator is used to place a second safety wire. A tract is then dilated using a $30 \mathrm{~F}$ balloon and a 17 or $20 \mathrm{~cm}$ Amplatz sheath is positioned into the calix depending on the skin to calix distance. Stone material is removed using an Olympus LUS-2 ultrasonic lithotripter (Olympus, Center Valley, PA) following which time the kidney is carefully inspected with a flexible nephroscope to visualize each and every calix. Upon completion, a 10F Cope nephrostomy tube is positioned in the kidney, and a 5F ureteral catheter is advanced down the ureter to facilitate access should secondary PCNL be required.

The morning following surgery, a noncontrast CT scan is performed to document tube position and stone burden. Patients with residual stone burden are taken back to the operating room for secondary PCNL within 24 to 48 hours. Once all stones have been cleared, an antegrade nephrostogram is performed to confirm renal drainage and the nephrostomy tube is removed before discharge.

\section{Outcome measures and statistical analysis}

We began by comparing patients in each BMI cohort across a range of demographic factors. We correlated the degree of comorbidity between groups by defining the proportion of patients with diagnoses for hypertension, renal insufficiency, diabetes, and gout. We further compared stone size measured as maximal stone dimension on CT, stone configuration (staghorn vs nonstaghorn), and stone analysis between groups. Stone analysis was performed by a single laboratory (Beck Laboratories, Greenwood, Indiana) with stones categorized based on predominant mineral subtype (e.g., calcium oxalate, calcium phosphate). The number of accesses performed at the time of primary PCNL and case duration (defined as time from surgical incision to final nephrostomy tube placement) were also recorded and compared as a measure of case complexity.

Our primary objective was to compare the outcomes of PCNL among the three patient cohorts. We assessed procedure efficacy by determining the proportion of patients in whom secondary PCNL was performed. As described earlier, secondary PCNL is performed in patients with any residual stone burden on postoperative $\mathrm{CT}$ and, thus, approximates the stone-free rate. We then compared mean overall complication rate stratified by Clavien index, rate of blood transfusion, and length of stay (LOS).

Statistical analysis was conducted with IBM $^{\circledR}$ SPSS $^{\circledR}$ Statistics, Version 22. We performed chi-square test for categorical variables and ANOVA for continuous variables using two-sided significance test with alpha set at 0.05 for all comparisons.

\section{Results}

We identified a total of 1152 patients of which 254 (22.0\%) were classified as ideal, $840(73.0 \%)$ as overweight, and 58 $(5.0 \%)$ as superobese based on BMI. The mean BMI in the ideal, overweight, and superobese cohorts was 22.3 (range 18.5-25), 32.9 (range 25.1-49.9), and 56.6 (range 50-75.9), respectively. While older patients were more heavily represented in the overweight cohort, a significantly greater proportion of females were found in the superobese cohort. Comorbid conditions were present in increasing proportions as BMI increased, such that those in the superobese cohort had significantly higher rates of hypertension, diabetes, and gout relative to the overweight and ideal cohort, respectively. While a staghorn stone configuration was more common in the superobese cohort, stone size and case complexity, indicated by proportion of cases requiring more than one access and case duration, did not differ between groups (Table 1). Stone analysis data are presented in Table 2. Calcium phosphate stones were more common in patients in the ideal cohort, while a greater proportion of uric acid stones were observed in the overweight and superobese cohorts.

Surgical efficacy was similar between groups with $47.2 \%$, $42.0 \%$, and $38.0 \%$ of ideal, overweight, and superobese patients requiring secondary PCNL $(p=0.25)$. The overall mean complication rate was not statistically different between groups (12.6\% ideal vs $12.8 \%$ overweight vs $15.5 \%$ superobese; $p=0.66)$. Table 3 indicates the breakdown of complications stratified by Clavien grade. The majority of complications observed were relatively minor (Clavien grade 1 or 2) and no difference in complication severity was observed between BMI groups (Fig. 1). There was no difference observed between ideal, overweight, or superobese patients relative to mean rate of blood transfusion $(4.3 \% \mathrm{vs} 3.1 \% \mathrm{vs}$ $3.4 \% ; p=0.63$ ) or LOS (2.5 days vs 2.4 days vs 3.0 days; $p=0.12$ ).

\section{Discussion}

In the largest single-institution study to date, we investigated the outcomes of PCNL in more than 1150 subjects across a range of BMI extremes. In particular, we compared 
Table 1. Comparison of Mean Demographics, Comorbidity, and Case Complexity Between Groups

\begin{tabular}{|c|c|c|c|c|}
\hline & $\begin{array}{c}\text { Ideal BMI } \\
18.5-25 \\
(\mathrm{n}=254)\end{array}$ & $\begin{array}{c}\text { Overweight } \\
\text { BMI 25.1-49.9 } \\
(\mathrm{n}=840)\end{array}$ & $\begin{array}{c}\text { Superobese } \\
\text { BMI >50 } \\
(\mathrm{N}=58)\end{array}$ & $p$ \\
\hline Age (years) & 50.9 & 54.7 & 52.4 & $<0.01$ \\
\hline Male $(\%)$ & 42.1 & 53.5 & 25.9 & $<0.01$ \\
\hline Hypertension (\%) & 24.4 & 51.5 & 60.6 & $<0.01$ \\
\hline Renal insufficiency (\%) & 2.4 & 1.8 & 3.0 & 0.69 \\
\hline Diabetes $(\%)$ & 6.2 & 24.4 & 43.9 & $<0.01$ \\
\hline Gout $(\%)$ & 0.7 & 4.6 & 6.1 & $<0.01$ \\
\hline Stone size (range, $\mathrm{cm}$ ) & $2.6(0.3-10.7)$ & $2.6(0.3-9.4)$ & $2.8(0.3-6.0)$ & 0.21 \\
\hline Staghorn $(\%)$ & 28 & 33.5 & 43.9 & 0.04 \\
\hline$>1$ Access $(\%)$ & 35 & 32.3 & 34.5 & 0.69 \\
\hline Case duration (minutes) & 125.3 & 128 & 126.7 & 0.78 \\
\hline
\end{tabular}

$\mathrm{BMI}=$ body mass index .

surgical outcomes in the superobese against those with lesser BMI, an area that has not been previously reported. Superobese patients more often had staghorn calculi, possibly reflecting the referral nature of our practice and lack of experience in community settings with these challenging patients. The superobese patients also suffered from higher degrees of comorbidity than their overweight or ideal weight counterparts and had a higher proportion of uric acid stones, a finding consistent with reports from other investigators. ${ }^{22}$ Despite these facts, surgical outcomes did not differ. Furthermore, overall complication rates and severity were comparable between BMI groups indicating that PCNL can be safely performed even at BMI extremes.

Our results are consistent with other published studies, which report no difference in stone-free rates or operative complications as BMI increases. ${ }^{12,13,18}$ Interestingly, in the largest study to date on the topic, Fuller et al., in a large, multicenter study from the Clinical Research Office of the Endourological Society (CROES), found that stone-free rates were inversely related to increasing BMI, although with no difference in complication rates. This disparity is possibly related to the single- $v s$ multi-institutional nature of the two studies. While we report outcomes from a single, tertiary referral center with expertise in urinary stone disease, the CROES study synthesizes data from 96 centers, some of which may perform few PCNL on obese patients, thus

Table 2. Stone Analysis Comparison BY BoDy MASS INDEX GROUP

\begin{tabular}{|c|c|c|c|c|}
\hline & $\begin{array}{c}\text { Ideal BMI } \\
18.5-25 \\
(\%)\end{array}$ & $\begin{array}{c}\text { Overweight } \\
\text { BMI } \\
25.1-49.9 \\
(\%)\end{array}$ & $\begin{array}{c}\text { Superobese } \\
\text { BMI } \\
>50(\%)\end{array}$ & $\mathrm{p}$ \\
\hline $\begin{array}{l}\text { Calcium } \\
\text { oxalate }\end{array}$ & 43.4 & 45.4 & 43.8 & 0.98 \\
\hline $\begin{array}{l}\text { Calcium } \\
\text { phosphate }\end{array}$ & 39.7 & 31.6 & 34.4 & 0.04 \\
\hline Uric acid & 3.1 & 11.4 & 12.5 & $<0.01$ \\
\hline Struvite & 5.2 & 4.0 & 3.1 & 0.59 \\
\hline Cystine & 2.4 & 2.8 & 0 & 0.39 \\
\hline Other & 1.4 & 1.2 & 1.6 & 0.94 \\
\hline Unknown & 4.8 & 3.6 & 4.6 & 0.86 \\
\hline
\end{tabular}

skewing outcomes to give the impression of an inverse association.

The finding that PCNL outcomes are satisfactory in even superobese patients speaks to the favorable intersection between equipment advances with the training and expertise of modern endourologists. Recently, Streeper and coworkers reported their outcomes in 31 patients with a BMI greater than 50 (mean 59.1). They noted that access to specialized equipments such as extra-long access needles, Amplatz sheaths, and nephroscopes was of paramount importance and, admirably, they reported no failures to obtain access. ${ }^{16}$ In a similar study, also including patients with a BMI in excess of 50 , Keheila and associates reported their outcomes of 21 PCNL in patients with a mean BMI of 57.2. Stone-free rates $\sim 87 \%$ and complication rates were comparable to contemporary series. They emphasize the importance of the entire care team, incorporating an anesthesiologist comfortable with prone positioning and airway concerns in obese patients. $^{17}$

While the two previously described studies have demonstrated the feasibility of PCNL in even the largest patients, ours is the first to indicate acceptable outcomes with PCNL in a direct comparison between superobese patients and those with lower BMI. These findings are important in the context of the increasing use of flexible ureteroscopy, especially for larger renal stones. ${ }^{23,24}$ In fact, investigators have suggested that ureteroscopy may indeed be the treatment of choice for obese patients with renal stones based on perceived

TAble 3. Number of Complications in EACH Group Stratified by Clavien System

\begin{tabular}{|c|c|c|c|}
\hline & $\begin{array}{c}\text { Ideal BMI } \\
18.5-25 \\
(\mathrm{n}=32)\end{array}$ & $\begin{array}{c}\text { Overweight } \\
\text { BMI } \\
25.1-49.9 \\
(\mathrm{n}=108)\end{array}$ & $\begin{array}{c}\text { Superobese } \\
B M I>50 \\
(\mathrm{n}=9)\end{array}$ \\
\hline Clavien I (\%) & $12(37.5)$ & $44(40.7)$ & $4(44.4)$ \\
\hline Clavien II (\%) & $9(28.1)$ & $31(28.7)$ & $2(22.2)$ \\
\hline Clavien IIIa (\%) & $6(18.8)$ & $18(16.7)$ & $1(11.1)$ \\
\hline Clavien IIIb (\%) & $4(12.5)$ & $9(8.3)$ & $1(11.1)$ \\
\hline Clavien Iva (\%) & $1(3.1)$ & $3(2.8)$ & $0(0)$ \\
\hline Clavien IVb (\%) & $0(0)$ & 2 (1.9) & $1(11.1)$ \\
\hline Clavien V $(\%)$ & $0(0)$ & $1(0.9)$ & $0(0)$ \\
\hline
\end{tabular}




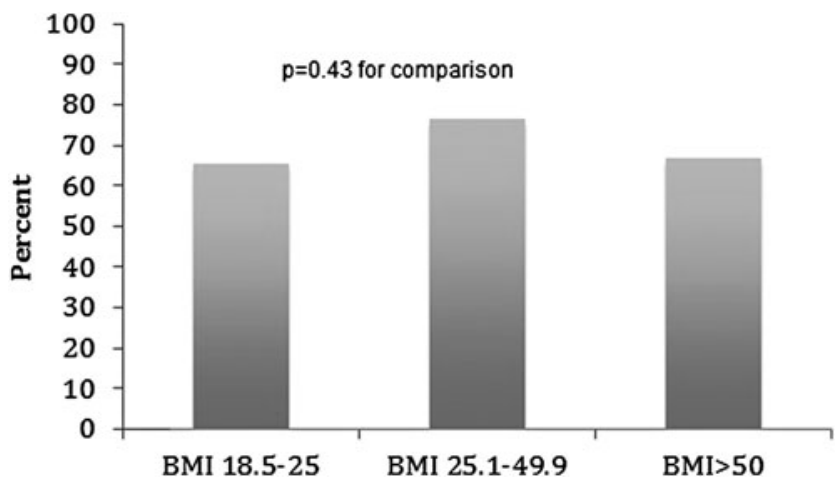

FIG. 1. Among patients with complications, proportion with Clavien Grade $<3$.

difficulties associated with PCNL in this patient group. ${ }^{19}$ Doizi et al. retrospectively reviewed their experience with ureteroscopy in normal weight, obese, and morbidly obese patients and found that success rates overall were roughly $68 \%$ for a single procedure. Complications were rare, reported at $2 \%$, leading investigators to suggest that ureteroscopy may be the preferred treatment for renal stones in obese patients.

This assertion must be tempered by several factors. First, success rate was defined by the absence of residual fragments $>2 \mathrm{~mm}$, an outcome measure of debate among urologists. ${ }^{25}$ Furthermore, many patients underwent a plain radiograph and ultrasound at follow-up, a limitation conceded by the investigators. Second, only 14 procedures were included in the morbidly obese group, defined as BMI greater than 40, limiting generalizability of these outcomes, especially given the relatively low success rate following two procedures in this group of $78.6 \%$. Finally, although complication rates were certainly lower than we report for PCNL, other studies describing ureteroscopy in obese patients indicate complication rates comparable to our results. ${ }^{26}$

In our experience, although the superobese patient provides unique challenges, we do not typically deviate from our normal procedure. The patient is positioned prone because although peak inspiratory airway pressures are known to be increased in obese patients, this is independent of prone or supine positioning. ${ }^{27}$ Care is taken to judiciously pad all potential pressure points to prevent nerve or tissue injury and the patient is securely fastened to the table to prevent shifting. Like other investigators, we employ long instruments when necessary and perform judicious flexible nephroscopy, unlike any other PCNL. In the event that even with long instruments the calix of interest is unable to be reached, a larger skin incision can be made to prevent hubbing of the access needle or nephroscope against the skin and facilitate further advancement of the Amplatz sheath. Exit strategies are of particular importance in the superobese patient as nephrostomy tube dislodgement is common. ${ }^{28}$ Since secondary PCNL is performed in more than one third of these patients, durable access to the collecting system is vital. Efforts to position the $10 \mathrm{~F}$ Cope loop in a polar calix opposite that which was punctured, rather than the renal pelvis, may limit tube expulsion and routine placement of a $5 \mathrm{~F}$ catheter down the ipsilateral ureter.
Our study must be viewed within the context of some limitations. First, although the database is prospectively maintained, we report retrospective results. Thus, our results may be vulnerable to bias inherent in retrospective studies. This limitation should be mitigated, to a degree, by the large sample size presented in this study. Second, we report outcomes measured by the proportion of patients who went on to require a secondary PCNL rather than stone-free rate. While stone-free rate is the most widely accepted outcome measure for renal stone surgery, its definition is not without controversy, namely what is truly considered stone free. We judiciously map the collecting system with a flexible nephroscope at the time of secondary PCNL and perform basket extraction of all stone fragments. It is assumed that results of secondary PCNL correlate with stone-free rate. While the number of surgeons (13) performing PCNL in this study is large, and could introduce procedural variability impacting results, the vast majority of cases $(>95 \%)$ were performed by a single surgeon (J.E.L.). Finally, we report our experience from a tertiary referral center and perform several hundred PCNL annually. As such, our outcomes may not be generalizable to all practicing urologists in whom exposure to superobese patients needing percutaneous surgery may be significantly less frequent.

\section{Conclusion}

PCNL can be safely and effectively performed in superobese patients, with no significant differences in complications or outcomes when compared to overweight or ideal body weight individuals. Appropriate surgical planning with particular attention to proper instrumentation is important to ensure a desirable outcome. In the absence of a prospective direct comparison between PCNL and ureteroscopy for large renal stones in superobese patients, it is likely that urologists will choose whichever procedure they feel best trained to perform, although referral to a center with expertise in PCNL should be strongly considered in these patients.

\section{Acknowledgment}

This work submitted for publication was previously presented in abstract form at the 2016 AUA Annual Meeting in San Diego, California.

\section{Author Disclosure Statement}

J.E.L.: Consultant for Boston Scientific Corporation on Lithovue project. All other authors have no competing financial interests.

\section{References}

1. Preminger GM, Assimos DG, Lingeman JE, et al. Chapter 1: AUA guideline on management of staghorn calculi: Diagnosis and treatment recommendations. J Urol 2005;173: 1991-2000.

2. Turk C, Knoll T, Petrik A. Guidelines on Urolithiasis, EAU Guidelines-Urolithiasis 2014. www.uroweb.org. Available at: www.uroweb.org/gls/pdf/22\%20Urolithiasis_LR.pdf. Accessed: February 26, 2015.

3. Armitage JN, Irving SO, Burgess NA, et al. Percutaneous nephrolithotomy in the United kingdom: Results of a prospective data registry. Eur Urol 2012;61:1188-1193. 
4. la Rosette de J, Assimos D, Desai M, et al. The Clinical Research Office of the Endourological Society Percutaneous Nephrolithotomy Global Study: Indications, complications, and outcomes in 5803 patients. J Endourol 2011; 25:11-17.

5. Michel MS, Trojan L, Rassweiler JJ. Complications in percutaneous nephrolithotomy. Eur Urol 2007;51:899-906; discussion 906.

6. Patel T, Kozakowski K, Hruby G, et al. Skin to stone distance is an independent predictor of stone-free status following shockwave lithotripsy. J Endourol 2009;23:1383-1385.

7. Albala DM, Assimos DG, Clayman RV, et al. Lower pole I: A prospective randomized trial of extracorporeal shock wave lithotripsy and percutaneous nephrostolithotomy for lower pole nephrolithiasis-initial results. J Urol 2001;166: 2072-2080.

8. Ogden CL, Carroll MD, Flegal KM. Prevalence of obesity in the United States. JAMA 2014;312:189-190.

9. Semins MJ, Shore AD, Makary MA, et al. The association of increasing body mass index and kidney stone disease. $\mathrm{J}$ Urol 2010;183:571-575.

10. Taylor EN, Stampfer MJ, Curhan GC. Obesity, weight gain, and the risk of kidney stones. JAMA 2005;293:455462.

11. Mosli HA, Mosli HH. Increased body mass index is associated with larger renal calculi. Urology 2012;80:974-977.

12. Faerber GJ, Goh M. Percutaneous nephrolithotripsy in the morbidly obese patient. Tech Urol 1997;3:89-95.

13. El-Assmy AM, Shokeir AA, El-Nahas AR, et al. Outcome of percutaneous nephrolithotomy: Effect of body mass index. Eur Urol 2007;52:199-204.

14. Fuller A, Razvi H, Denstedt JD, et al. The CROES percutaneous nephrolithotomy global study: The influence of body mass index on outcome. J Urol 2012;188:138-144.

15. Fuller A, Razvi H, Denstedt JD, et al. The clinical research office of the endourological society percutaneous nephrolithotomy global study: Outcomes in the morbidly obese patient-A case control analysis. Can Urol Assoc J 2014; 8:E393-E397.

16. Streeper NM, Radtke AC, Penniston KL, et al. Percutaneous nephrolithotomy in patients with $\mathrm{BMI}>50$ : Single surgeon outcomes and feasibility. Urology 2015;87:33-39.

17. Keheila M, Leavitt D, Galli R, et al. Percutaneous nephrolithotomy in super obese patients (body mass index $\geq 50 \mathrm{~kg} / \mathrm{m}(2))$ : Overcoming the challenges. BJU Int 2016;117: 300-306.

18. Koo BC, Burtt G, Burgess NA. Percutaneous stone surgery in the obese: Outcome stratified according to body mass index. BJU Int 2004;93:1296-1299.

19. Doizi S, Letendre J, Bonneau C, et al. Comparative study of the treatment of renal stones with flexible ureterorenoscopy in normal weight, obese, and morbidly obese patients. Urology 2015;85:38-44.

20. Miller NL, Matlaga BR, Lingeman JE. Techniques for fluoroscopic percutaneous renal access. J Urol 2007;178: $15-23$.

21. Tayeb El MM, Knoedler JJ, Krambeck AE, et al. Vascular complications after percutaneous nephrolithotomy: 10 years of experience. Urology 2015;85:777-781.

22. Lee S-C, Kim Y-J, Kim T-H, et al. Impact of obesity in patients with urolithiasis and its prognostic usefulness in stone recurrence. J Urol 2008;179:570-574.

23. Matlaga BR; American Board of Urology. Contemporary surgical management of upper urinary tract calculi. J Urol 2009;181:2152-2156.

24. Dauw CA, Simeon L, Alruwaily AF, et al. Contemporary practice patterns of flexible ureteroscopy for treating renal stones: Results of a worldwide survey. J Endourol 2015; 29:1221-1230.

25. Pearle MS. Is ureteroscopy as good as we think? J Urol 2016; 195:823-824.

26. Ishii H, Couzins M, Aboumarzouk O, et al. Outcomes of systematic review of ureteroscopy for stone disease in the obese and morbidly obese population. J Endourol 2016; 30:135-145.

27. Siev M, Motamedinia P, Leavitt D, et al. Does peak inspiratory pressure increase in the prone position? An analysis related to body mass index. J Urol 2015;194:13021306.

28. Bayne D, Taylor ER, Hampson L, et al. Determinants of nephrostomy tube dislodgment after percutaneous nephrolithotomy. J Endourol 2015;29:289-292.

Address correspondence to: James E. Lingeman, MD, FACS Department of Urology Indiana University School of Medicine 1801 North Senate Blvd., Suite 220 Indianapolis, IN 46202

E-mail: jlingeman@iuhealth.org

$$
\begin{aligned}
& \text { Abbreviations Used } \\
& \text { BMI }= \text { body mass index } \\
& \text { CROES }= \text { Clinical Research Office of the } \\
& \text { Endourological Society } \\
& \mathrm{CT}=\text { computed tomography } \text { LOS }=\text { length of stay } \\
& \text { PCNL }=\text { percutaneous nephrolithotomy }
\end{aligned}
$$

